\title{
Knowledge of HIV Transmission and Associated Factors among HIV-Positive and HIV-Negative Patients in Rural Kenya
}

Steven Y Hong ${ }^{1,2^{*}}$, Daria Thompson ${ }^{2}$, Christine Wanke ${ }^{1,2}$, Gloria Omosa ${ }^{3}$, Michael R Jordan ${ }^{1,2}$, Alice M Tang ${ }^{2}$, Shem Patta ${ }^{3}$, Ben Mwero ${ }^{3}$, Innocent Mjomba ${ }^{3}$ and Mkaya Mwamburi ${ }^{2,3}$

${ }^{1}$ Division of Geographic Medicine and Infectious Diseases, Tufts Medical Center, Boston, USA

${ }^{2}$ Department of Public Health and Community Medicine, Tufts University School of Medicine, Boston, USA

${ }^{3}$ Clinical Research Division, Voi Research Centre, Voi, Kenya

\section{Summary}

Knowledge of HIV transmission is a prerequisite to practicing safer behaviors to prevent HIV infections and may be expected to vary by region because of cultural and socioeconomic determinants. A cross-sectional study was conducted in rural Kenya using a standardized questionnaire assessing HIV transmission knowledge, sociodemographic and other characteristics. Participants were recruited from the voluntary counseling and testing clinic and the general hospital population of Moi District Hospital. "High" HIV transmission knowledge scorers ( $\geq 81 \%)$ (Mean score) were compared with "low" scorers (<81\%). Bivariate and multivariate logistic regression analyses were performed to examine factors associated with HIV transmission knowledge. Of 214 participants, 70 (33\%) were HIV-positive, 104 (49\%) were HIV-negative, and 40 (19\%) did not know. Factors associated with low knowledge in multivariate analyses were lower education (OR 2.36, $\mathrm{Cl}$ 1.03-5.46), lower household money on healthcare (OR 2.03, Cl 1.28-3.21), higher clinic transportation costs (OR 3.14, Cl 1.20-9.82), sex without a condom (OR 2.18, Cl 1.12-4.26), positive HIV status vs. negative (OR 2.50, $\mathrm{Cl}$ 1.22-5.26) and positive HIV status vs. unknown (OR 3.57 , CI 1.33-9.09). Mean HIV transmission knowledge score was relatively high; however, a large proportion of patients demonstrated low knowledge. Identifying individuals at risk for low knowledge will support targeted HIV education and prevention programs.

\section{Introduction}

Although knowledge about HIV transmission and acquisition cannot ensure the practice of "safe sex" or other HIV infection riskreduction strategies, it is a necessary prerequisite towards safer behaviors among HIV-negative and HIV-positive individuals [1]. Therefore, ignorance about how HIV is transmitted and acquired is detrimental to HIV prevention efforts. HIV transmission knowledge among HIV-negative individuals is essential to reduce risk of infection; and HIV transmission knowledge among HIV-positive individuals is necessary to reduce risk of super-infection, as well as to prevent spread of infection. Identification of correlates of poor HIV transmission knowledge in both HIV-positive and HIV-negative individuals will aid in developing effective measures to improve health knowledge about HIV transmission, thus potentially decreasing HIV incidence.

Many studies have investigated HIV knowledge among uninfected individuals [2-4]. However, less data assessing HIV knowledge in HIVinfected patients are available. Existing literature demonstrates that some HIV-positive patients continue to engage in risky behaviors [57], however, little information is available regarding HIV transmission knowledge among HIV-positive patients and the role it may play in altering risky behavior $[8,9]$. Additionally, little published information is available on the factors associated with HIV transmission knowledge among those infected with HIV.

Of the 33 million people infected with HIV worldwide, the majority live within resource-limited settings [10]. Of the 39 million people in Kenya [11], 6\% of adults age 15-49 are infected with HIV. The estimated number of incident cases of HIV infections in Kenya in 2009 was 120,000 children and adults [12]. HIV in Kenya is mainly transmitted through heterosexual contact. Therefore, HIV prevention programs in Kenya have focused messages on three aspects of behavior: delaying sexual debut for young persons (abstinence), limiting the number of sexual partners (be faithful to one partner), and using condoms, also labeled "ABC" [12].
According to the 2008-09 Kenya Demographics and Health Survey [12], knowledge of methods to avoid HIV transmission is generally high. For example, $88 \%$ of women and $90 \%$ of men know that abstaining from sex reduces chances of getting HIV. Similarly, 92\% of women and 93\% of men know that limiting sex to one faithful partner reduces chances of acquiring HIV. Additionally, $75 \%$ of women and $81 \%$ of men know that the risk of acquiring HIV can be reduced by using condoms. However, "comprehensive knowledge" about HIV was lower (males 56\%, females 49\%), defined as knowing that both consistent use of condoms and also having just one uninfected partner can reduce the chance of infection, knowing that a healthy-looking person can have HIV, and knowing that HIV cannot be transmitted by mosquito or by sharing food [12]. It has been shown in the literature that even in populations with accurate knowledge about HIV transmission, high levels of incorrect knowledge about HIV transmission can cooccur largely independent of the accurate knowledge [13]. Therefore, HIV education and prevention programs must seek to assess for and address specific inaccurate beliefs about HIV transmission that may be coexisting with accurate knowledge as part of their efforts to promote behavior change.

${ }^{*}$ Corresponding author: Steven Y. Hong MD, MPH, Department of Public Health and Community Medicine, Tufts University School of Medicine, 150 Harrison Avenue, Jaharis 2, Boston, MA 02111, USA, Tel: 1-617-636-0827; Fax: 1-617-6363810; E-mail: shong@tuftsmedicalcenter.org

Received July 04, 2012; Accepted September 20, 2012; Published September 24, 2012

Citation: Hong SY, Thompson D, Wanke C, Omosa G, Jordan MR, et al. (2012) Knowledge of HIV Transmission and Associated Factors among HIV-Positive and HIV-Negative Patients in Rural Kenya. J AIDS Clinic Res 3:170. doi:10.4172/21556113.1000170

Copyright: ( 2012 Hong SY, et al. This is an open-access article distributed under the terms of the Creative Commons Attribution License, which permits unrestricted use, distribution, and reproduction in any medium, provided the original author and source are credited. 
Citation: Hong SY, Thompson D, Wanke C, Omosa G, Jordan MR, et al. (2012) Knowledge of HIV Transmission and Associated Factors among HIVPositive and HIV-Negative Patients in Rural Kenya. J AIDS Clinic Res 3:170. doi:10.4172/2155-6113.1000170

Page 2 of 6

Data in Kenya indicate that rural dwellers are less knowledgeable about all methods of reducing the risk of HIV infection than their urban counterparts [12]. Considering that more than $75 \%$ of the Kenyan population lives in rural settings [14], more data are needed about HIV transmission knowledge and correlates in these settings. The objective of this study was to estimate the level of HIV transmission knowledge among HIV-positive and HIV-negative individuals in a rural Kenyan setting and to assess for factors associated with low HIV transmission knowledge.

\section{Methods}

\section{Study population}

We conducted a cross-sectional study utilizing a structured questionnaire in a rural region of Kenya. Between June and August 2010, a convenience sample of HIV-positive and HIV-negative adults $\geq$ 18 year of age was recruited from the voluntary counseling and testing clinic and the general hospital population of Moi District Hospital in Voi which is located in the Taita-Taveta County, one of the 47 counties of Kenya. Taita-Taveta County has a population of 300,000 and HIV prevalence of 5.6\% (Ministry of Health Taita District, Kenya, personal communication). After obtaining written informed consent, subjects were interviewed in a private room by a trained interviewer. Ethical approval was obtained from the institutional review board at Tufts University School of Medicine, Boston, USA and the Kenyatta National Hospital/University of Nairobi, Kenya.

\section{Study questionnaires}

A pre-tested questionnaire assessing socio-demographic characteristics, HIV transmission knowledge, access to healthcare, and substance abuse, was administered. The questionnaire was translated into Swahili and back-translated by a separate translator to ensure accuracy. The questionnaire was administered in English or Swahili depending on the participant's preference.

HIV transmission knowledge questions were adapted from a study conducted in a Prevention and Access to Care and Treatment program based in the Division of Social Medicine and Health Inequalities at the Brigham and Women's Hospital, Boston, USA [1]. We utilized the 22item combined scale which had been developed based on two scales which demonstrated good reliability and validity $[15,16]$; internal consistency reliability for the combined scale was estimated at 0.84 (Cronbach's alpha). Questions were not significantly changed, to allow for comparability.

HIV transmission knowledge score was estimated by calculating the percent of correct responses on a true/false scale. Knowledge score was summarized in two ways: (1) as the proportion of correct responses over the total number of possible responses from all participants [1] and (2) as the mean of individual scores (calculated only among the 214 individuals who completed the entire 22-item knowledge scale). "High" HIV transmission knowledge scorers i.e. those with $\geq 81 \%$ (mean score) were compared with "low" scorers $(<81 \%)$. Eighty-one percent was used as a cut-off because it was the mean knowledge score for this study population and approximately equal-sized groups for 'high' versus 'low' knowledge were generated for the analysis [1]. Bivariate analyses were performed to examine the associations between HIV transmission knowledge and other factors. Multivariate logistic regression analyses were performed to control for potential confounders. Factors with statistically significant associations or potential confounders were considered for multivariate models. Results were analyzed using SAS version 11 .

\begin{tabular}{|c|c|c|}
\hline QUESTION & $\mathrm{n} / \mathrm{N}^{*}(\%)$ & $\begin{array}{l}\text { Correct } \\
\text { answer }\end{array}$ \\
\hline \multicolumn{3}{|l|}{ Knowledge of Sexual Transmission } \\
\hline $\begin{array}{l}\text { Having more than one sexual partner without using } \\
\text { protection will increase a person's chances of } \\
\text { becoming infected with HIV }\end{array}$ & $226 / 230(98.3)$ & $\mathrm{T}$ \\
\hline $\begin{array}{l}\text { A person can be exposed to the HIV in one sexual } \\
\text { contact }\end{array}$ & $215 / 229(93.9)$ & $\mathrm{T}$ \\
\hline $\begin{array}{l}\text { The main body fluids that contain HIV are semen, } \\
\text { blood, and vaginal secretions }\end{array}$ & $223 / 231(96.5)$ & $\mathrm{T}$ \\
\hline Oral intercourse carries risk for HIV transmission & 188/230 (81.8) & $\mathrm{T}$ \\
\hline Pre-ejaculatory fluids carry the AIDS virus & $214 / 225(95.1)$ & $\mathrm{T}$ \\
\hline $\begin{array}{l}\text { Only receptive (passive) anal intercourse transmits } \\
\text { HIV }\end{array}$ & $118 / 229(51.5)$ & $\mathrm{F}$ \\
\hline Mean score (for correct responses) & \multicolumn{2}{|c|}{$1184 / 1374(86.2)$} \\
\hline \multicolumn{3}{|l|}{ Knowledge of Prevention } \\
\hline $\begin{array}{l}\text { A person can protect him/herself from HIV infection by } \\
\text { using a latex condom during sex }\end{array}$ & $187 / 230(81.3)$ & $\mathrm{T}$ \\
\hline Condoms makes intercourse completely safe & 93/231 (40.3) & $\mathrm{F}$ \\
\hline $\begin{array}{l}\text { Showering after sex greatly reduces the transmission } \\
\text { of HIV }\end{array}$ & $213 / 231(92.2)$ & $\mathrm{F}$ \\
\hline $\begin{array}{l}\text { Keeping in good physical condition is the best way to } \\
\text { prevent exposure to HIV }\end{array}$ & $120 / 230(52.2)$ & $\mathrm{F}$ \\
\hline Mean score (for correct responses) & \multicolumn{2}{|c|}{$613 / 922(66.5)$} \\
\hline \multicolumn{3}{|l|}{ Knowledge of Blood Transmission } \\
\hline $\begin{array}{l}\text { If someone infected with HIV uses injection drugs and } \\
\text { shares needles, he/she can spread HIV }\end{array}$ & $224 / 231(97.0)$ & $\mathrm{T}$ \\
\hline HIV does not penetrate unbroken skin & $164 / 230(71.3)$ & $\mathrm{T}$ \\
\hline $\begin{array}{l}\text { Donating blood carries a risk of getting HIV for the } \\
\text { donor }\end{array}$ & $84 / 230(36.5)$ & $\mathrm{F}$ \\
\hline Mean score (for correct responses) & \multicolumn{2}{|c|}{$472 / 691(68.3)$} \\
\hline \multicolumn{3}{|l|}{ Knowledge of HIV Testing } \\
\hline $\begin{array}{l}\text { A blood test is what tells you if you are infected with } \\
\text { HIV }\end{array}$ & $228 / 231(98.7)$ & $\mathrm{T}$ \\
\hline $\begin{array}{l}\text { If someone has a negative HIV test (meaning they } \\
\text { don't have HIV), that means they cannot get HIV }\end{array}$ & $201 / 226(88.9)$ & $\mathrm{F}$ \\
\hline $\begin{array}{l}\text { Someone can have a negative HIV blood test and still } \\
\text { have the virus }\end{array}$ & $212 / 229(92.6)$ & $\mathrm{T}$ \\
\hline Mean score (for correct responses) & \multicolumn{2}{|c|}{$641 / 686(93.4)$} \\
\hline \multicolumn{3}{|l|}{ Knowledge of Common Misconceptions } \\
\hline $\begin{array}{l}\text { Only homosexual ("gay") people can become infected } \\
\text { with HIV }\end{array}$ & $219 / 231(94.8)$ & $\mathrm{F}$ \\
\hline $\begin{array}{l}\text { A person can get HIV by sitting next to someone } \\
\text { who is infected with HIV or by touching or hugging } \\
\text { someone who is HIV infected }\end{array}$ & $223 / 231(96.5)$ & $\mathrm{F}$ \\
\hline You can always tell when a person is infected with HIV & $196 / 228(86.0)$ & $\mathrm{F}$ \\
\hline $\begin{array}{l}\text { Most persons exposed to the HIV virus know they are } \\
\text { exposed }\end{array}$ & $113 / 230(49.1)$ & $\mathrm{F}$ \\
\hline $\begin{array}{l}\text { If a person has HIV but doesn't know it, he/she can still } \\
\text { give it to someone else }\end{array}$ & $219 / 228(96.1)$ & $\mathrm{T}$ \\
\hline Mean score (for correct responses) & \multicolumn{2}{|c|}{ 1190/1379 (86.3) } \\
\hline Total mean score (for correct responses)\# & \multicolumn{2}{|c|}{$4100 / 5052(81.2)$} \\
\hline
\end{tabular}

\section{Results}

\section{Participant characteristics}

Two hundred thirty-one patients participated (Table 1); 82 (35\%) were from VCT; 214 participants had complete data on HIV transmission knowledge (i.e. all 22 items) (Table 2). Of these, 114 (53\%) were female. Mean age was 36.0 years (SD 10.5). Sixty-nine participants (32\%) were single. Seventy (33\%) were HIV-positive, 104 (49\%) were HIV-negative, and 40 (19\%) did not know their status. One hundred 


\begin{tabular}{|c|c|c|c|c|}
\hline Characteristics & $\begin{array}{l}\text { Knowledge } \\
\text { Score < 81\% } \\
(\mathrm{n}=96)\end{array}$ & $\begin{array}{l}\text { Knowledge } \\
\text { Score > 81\% } \\
(\mathrm{n}=118)\end{array}$ & P-Value & $\begin{array}{l}\text { Overall\# } \\
(\mathrm{n}=214)\end{array}$ \\
\hline Age (years), mean (SD) & $37.7 \pm 10.6$ & $34.6 \pm 10.3$ & 0.04 & $36.0(10.5)$ \\
\hline Sex (female), n (\%) & $53(55)$ & $61(52)$ & 0.61 & $114(53)$ \\
\hline Marital status (single), n (\%) & $29(30)$ & $40(34)$ & 0.32 & $69(32)$ \\
\hline $\begin{array}{l}\text { Education level (< Diploma), } \\
\text { n (\%) }\end{array}$ & $81(84)$ & $84(71)$ & 0.02 & $165(77)$ \\
\hline $\begin{array}{l}\text { Religion (Christian-Protestant), } \\
\text { n (\%) }\end{array}$ & $45(47)$ & $53(45)$ & 0.86 & $98(46)$ \\
\hline \multicolumn{5}{|l|}{ HIV status, $n(\%)$} \\
\hline Negative & $36(37)$ & $68(58)$ & 0.00 & $104(49)$ \\
\hline Positive & $47(49)$ & $23(19)$ & & $70(33)$ \\
\hline Unknown & $13(14)$ & $27(23)$ & & 40 (19) \\
\hline $\begin{array}{l}\text { Household HIV status (no one } \\
\text { with HIV), } \mathrm{n}(\%)\end{array}$ & $73(76)$ & $97(82)$ & 0.31 & $170(79)$ \\
\hline Alcohol use (none), n (\%) & 76 (79) & $78(66)$ & 0.03 & $154(72)$ \\
\hline $\begin{array}{l}\text { Recreational drug use (none), } \\
\mathrm{n}(\%)\end{array}$ & $77(80)$ & $97(83)$ & 0.61 & 174 (81) \\
\hline Current drug use (none), $\mathrm{n}(\%)$ & $90(94)$ & $115(98)$ & 0.08 & $205(96)$ \\
\hline Injection drug use (none), n (\%) & $91(95)$ & $118(100)$ & 0.01 & $209(98)$ \\
\hline \multicolumn{5}{|l|}{ Number of sex partners, n (\%) } \\
\hline None & $19(20)$ & $10(8)$ & 0.02 & $29(14)$ \\
\hline 1 partner & $47(49)$ & $76(64)$ & 0.02 & $123(58)$ \\
\hline$>1$ partner & $30(31)$ & $32(27)$ & 0.51 & $62(29)$ \\
\hline $\begin{array}{l}\text { Sex without a condom (mostly/ } \\
\text { always), } \mathrm{n}(\%)\end{array}$ & $42(44)$ & $30(25)$ & 0.01 & $72(34)$ \\
\hline $\begin{array}{l}\text { Sex for money or gifts (none), } \\
n(\%)\end{array}$ & $83(86)$ & $110(93)$ & 0.10 & $193(90)$ \\
\hline \multicolumn{5}{|l|}{$\begin{array}{l}\text { Monthly household income } \\
\left(\mathrm{Ksh}^{*}\right), \mathrm{n}(\%)\end{array}$} \\
\hline 0-999 & $47(51)$ & $43(38)$ & 0.01 & $90(42)$ \\
\hline 1000-1999 & $20(22)$ & $34(30)$ & & $54(25)$ \\
\hline 2000-2999 & $6(6)$ & $21(19)$ & & $27(13)$ \\
\hline$>3000$ & $20(22)$ & $15(13)$ & & $35(16)$ \\
\hline $\begin{array}{l}\text { Monthly household money on } \\
\text { healthcare (lowest quintile†), } \\
\text { n (\%) }\end{array}$ & $68(71)$ & $57(49)$ & 0.02 & $125(58)$ \\
\hline \multicolumn{5}{|l|}{$\begin{array}{l}\text { Transport cost to clinic }\left(\mathrm{Ksh}^{*}\right), \\
\mathrm{n}(\%)\end{array}$} \\
\hline $0-19$ & $47(49)$ & $69(58)$ & 0.03 & $116(54)$ \\
\hline 20-199 & $25(26)$ & $36(31)$ & & $61(29)$ \\
\hline$>200$ & $24(25)$ & $13(11)$ & & $37(17)$ \\
\hline \multicolumn{5}{|c|}{$\begin{array}{l}\text { Time travel to clinic (minutes), } \\
n(\%)\end{array}$} \\
\hline $0-29$ & $44(46)$ & $72(61)$ & 0.09 & 116 (54) \\
\hline $30-59$ & $36(38)$ & $32(27)$ & & $68(32)$ \\
\hline$>60$ & $16(17)$ & $14(12)$ & & 30 (14) \\
\hline
\end{tabular}

* Kenya Shillings (exchange rate on December 8, 2011, 1 USD $=89.2$ Ksh)

Overall numbers of participants are based on completed HIV transmission knowledge questionnaires.

$\dagger<500 \mathrm{Ksh} / \mathrm{month}$ vs. $\geq 500 \mathrm{Ksh} /$ month

Table 2: Participant characteristics and factors associated with HIV transmission knowledge, bivariate analysis.

seventy (79\%) did not have a household member with HIV. Most participants had an education level less than a Diploma (165, or $77 \%)$ (Diploma is equivalent of college level). Ninety (42\%) had a monthly household income of less than Kenya Shillings (Ksh) 1,000 and only 35 (16\%) had a monthly household income greater than Ksh 3,000. (Kenya's gross national income per capita per month $=$ US dollars 61.44 (Ksh 5,480.59 with exchange rate on December 8, 2011 of US Dollars 1 $=$ Ksh 89.20)) [17]. One hundred sixteen participants (54\%) spent less than Ksh 20 for travel costs to get the hospital and spent less than 30 minutes for travel. Thirty-seven patients (17\%) spent more than Ksh
200 for travel costs to the hospital, and 30 patients (14\%) spent more than 60 minutes for travel. More than half the participants (125, or 58\%) were in the lowest quintile of household money spent on healthcare.

Alcohol and injection drug use (IDU) were reported as very low in this population, with $154(72 \%)$ and 209 (98\%) reporting no alcohol or IDU respectively. Sixty-two patients (29\%) reported currently having more than one sex partner. One hundred ninety-three (90\%) participants reported not having sex for money or gifts.

\section{HIV transmission knowledge score}

Table 1 shows the individual items of the HIV transmission knowledge questionnaire and the proportion of participants who responded correctly. Mean HIV transmission knowledge score was $81.2 \%$. The mean of the individual HIV transmission knowledge scores (among 214 individuals completing the entire scale) was $80.9 \%$ (SD 11.2).

HIV transmission knowledge questions were divided into five categories including: knowledge of sexual transmission, knowledge of prevention, knowledge of blood transmission, knowledge of HIV testing, and common misconceptions. Mean scores for knowledge of sexual transmission (86.2\%), knowledge of HIV testing (93.4\%), and knowledge of common misconceptions $(86.3 \%)$ were high. However, mean scores for knowledge of prevention $(66.5 \%)$ and knowledge of blood transmission (68.3\%) were lower. (Table 1 )

Knowledge of sexual transmission was high, with over $80 \%$ responding correctly in 5 of the 6 questions in this category. However, only 118 of 229 (52\%) correctly responded false to the question "Only receptive (passive) anal intercourse transmits HIV." Knowledge of prevention was lower, with over $80 \%$ responding correctly in only 2 of the 4 questions in this category. Only 93 of 231 (40\%) correctly responded false to the question, "Condoms makes intercourse completely safe," and only 120 of 230 (52\%) correctly responded false to the question, "Keeping in good physical condition is the best way to prevent exposure to HIV." Knowledge of blood transmission was somewhat lower, with over $80 \%$ responding correctly in only 1 of the 3 questions in this category. Only 84 of 230 (37\%) correctly responded false to the question, "Donating blood carries a risk of getting HIV for the donor," and 164 of 230 (71\%) correctly answered "HIV does not penetrate unbroken skin." Knowledge of HIV testing was high, with over $80 \%$ responding correctly in 3 of 3 questions in this category. Knowledge of common misconceptions was high, with over $80 \%$ responding correctly in 5 of 6 questions for this category. Only 113 of 230 (49\%) correctly answered false to the question, "Most persons exposed to the HIV virus know they are exposed."

\section{Bivariate and multivariate analyses}

Of the 214 completing the HIV transmission knowledge questionnaire, 118 had high transmission knowledge (>81\%) and 96 had low transmission knowledge $(<81 \%)$ (Table 2$)$. The mean score of the high group was $88.8 \%$ (SD 6.5) and the low group was $71.3 \%$ (SD 7.7). A comparison of characteristics associated with high vs. low knowledge is shown in table 2. Significant factors associated with low transmission knowledge with bivariate analyses included: older age $(\mathrm{p}=0.04)$, lower education level $(<$ Diploma) $(\mathrm{p}=0.02)$, lower monthly household income $(\mathrm{p}=0.01)$, positive HIV status $(\mathrm{p}=0.00)$, no alcohol intake ( $\mathrm{p}=0.03)$, IDU ( $\mathrm{p}=0.01)$, having no sex partners ( $\mathrm{p}=0.02)$, having one sex partner $(\mathrm{p}=0.02)$, practicing sex mostly or always without a condom ( $\mathrm{p}=0.01$ ), lower monthly household money spent on healthcare $(\mathrm{p}=0.02)$, and higher costs associated with transportation to the clinic $(\mathrm{p}=0.03)$. 


\begin{tabular}{|l|l|l|}
\hline Factors & Odds Ratio (95\% Cl) & P-value \\
\hline Age & $1.02(0.99-1.06)$ & 0.17 \\
\hline Sex (female) & $1.23(0.60-2.50)$ & 0.57 \\
\hline Education level (< Diploma) & $2.36(1.03-5.46)$ & 0.04 \\
\hline Alcohol use (none) & $1.76(0.82-3.77)$ & 0.14 \\
\hline $\begin{array}{l}\text { Monthly household money on healthcare (lowest } \\
\text { quintile) }\end{array}$ & $2.03(1.28-3.21)$ & 0.00 \\
\hline $\begin{array}{l}\text { Transport cost to clinic (highest tertile vs lowest } \\
\text { tertile) }\end{array}$ & $3.14(1.20-9.82)$ & 0.02 \\
\hline $\begin{array}{l}\text { Transport cost to clinic (highest tertile vs middle } \\
\text { tertile) }\end{array}$ & $1.93(0.69-5.41)$ & 0.83 \\
\hline Sex without a condom (mostly/always) & $2.18(1.12-4.26)$ & 0.02 \\
\hline HIV status (positive vs negative) & $2.50(1.22-5.26)$ & 0.01 \\
\hline HIV status (positive vs unknown) & $3.57(1.33-9.09)$ & 0.01 \\
\hline Number of sex partners & $1.34(0.91-1.97)$ & 0.14 \\
\hline
\end{tabular}

Table 3: Multivariate logistic regression analysis showing factors associated with low HIV transmission knowledge.

\begin{tabular}{|c|c|c|}
\hline Factors & $\begin{array}{l}\text { Mean HIV transmission } \\
\text { knowledge score }(\%)\end{array}$ & Standard deviation \\
\hline \multicolumn{3}{|l|}{ HIV status } \\
\hline HIV positive & 75.6 & 11.0 \\
\hline HIV negative & 83.1 & 10.1 \\
\hline Status unknown & 84.7 & 11.0 \\
\hline \multicolumn{3}{|l|}{ Education } \\
\hline Low education (<Diploma) & 79.3 & 11.1 \\
\hline High education ( $\geq$ Diploma) & 86.6 & 9.7 \\
\hline \multicolumn{3}{|l|}{ Healthcare costs } \\
\hline$<500 \mathrm{Ksh} /$ month & 78.7 & 10.3 \\
\hline $500-1000 \mathrm{Ksh} / \mathrm{month}$ & 84.2 & 10.4 \\
\hline $1000-2000 \mathrm{Ksh} /$ month & 81.5 & 17.6 \\
\hline 2000-3000 Ksh/month & 83.8 & 12.8 \\
\hline >3000 Ksh/month & 93.2 & 3.2 \\
\hline \multicolumn{3}{|l|}{ Travel cost to clinic } \\
\hline 0-19 Ksh & 81.5 & 10.8 \\
\hline 20-199 Ksh & 81.7 & 12.4 \\
\hline$>200 \mathrm{Ksh}$ & 78.0 & 10.2 \\
\hline \multicolumn{3}{|l|}{ Condom use } \\
\hline Mostly/always & 79.2 & 11.0 \\
\hline Never/rarely/sometimes & 81.9 & 11.2 \\
\hline
\end{tabular}

Table 4: Mean HIV transmission knowledge scores for significant factors in multivariate logistic regression.

Factors associated with low transmission knowledge with multivariate analyses (Table 3$)$ were lower education level $(<$ Diploma) (OR 2.36, CI 1.03-5.46), spending less household money on healthcare (OR 2.03, CI 1.28-3.21), higher costs associated with transportation or travel to the clinic (OR 3.14, CI 1.20 - 9.82), practicing sex mostly or always without a condom (OR 2.18, CI 1.12-4.26), positive HIV status vs. negative (OR 2.50, CI 1.22- 5.26) and positive HIV status vs. status unknown (OR 3.57, CI 1.33-9.09). Mean HIV transmission knowledge scores for significant factors in multivariate logistic regression are described in table 4.

\section{Discussion}

The objective of this study was to estimate the level of HIV transmission knowledge among HIV-positive and HIV-negative individuals attending a healthcare facility in a rural setting in Kenya and to assess for factors associated with low HIV transmission knowledge. The mean HIV transmission knowledge score was relatively high and was very similar to that found utilizing the same knowledge scale in a resource-limited setting in Boston and India $[1,18]$. Respondents performed well on questions about knowledge of sexual transmission, with the majority knowing about the risk of HIV transmission from sexual contact, about the risk of multiple sex partners, and about the risk of contact with which certain body fluids. However, we observed limitations in the area of receptive anal intercourse that may have placed some patients at risk of acquiring infection or transmitting the virus to others. Men who have sex with men and prison populations contribute $15 \%$ of new HIV infections. Furthermore, it has generally been reported that the epidemic in Kenya is driven primarily by heterosexual relations [12]. However, to answer incorrectly to the question, "Only receptive anal intercourse transmits HIV," would indicate a gap in knowledge that is important even in people not engaging in anal intercourse, as they may believe that other forms of unprotected sex would be "safe".

Respondents performed worse on questions about knowledge of prevention. Although most people knew the general message that condoms offer protection from HIV, of concern was that many people thought the use of condoms made intercourse completely safe and that keeping in good physical condition was the best way to prevent exposure to HIV. These responses may reflect an understanding of the general message about condoms without grasping the nuanced risk of condom failure. Also, people may have understood the general message of the benefit of good physical conditioning without grasping the specific information that good physical conditioning does not prevent the acquisition of HIV.

Respondents performed poorly on questions about knowledge of blood transmission. Although most respondents knew that IDU and sharing of needles carried a risk of spreading HIV, many believed donating blood carried a risk of getting HIV for the donor, and a significant proportion of respondents believed that HIV penetrates unbroken skin. These misconceptions can have a significant effect on the willingness of individuals to donate blood. Additionally, misconceptions about HIV penetrating unbroken skin can have implications on stigma and how people living with HIV are treated. These responses reflect good understanding of the general message of parenteral transmission of HIV without grasping some of the more specific information about the inability of the virus to penetrate intact skin and the current use of proper phlebotomy techniques in Kenya [19]. These data show that further content-based education initiatives should be targeted at common misconceptions that may exist alongside correct knowledge.

Respondents performed well on questions on HIV testing. Respondents did not only know the general knowledge that HIV blood testing can indicate if someone is infected with HIV, but they also knew that a person could have HIV and still have a negative HIV test. It is not clear whether or not respondents understood the reasons why false negative tests occur, but these responses demonstrate a good grasp of important basic concepts surrounding HIV testing.

Respondents performed well on questions pertaining to common misconceptions. Importantly, respondents seemed to know the specific ways HIV is and is not spread. They also knew that a person could be infected with HIV and not know they are infected. However, a majority of respondents stated that they believed most people who were exposed to HIV knew they were exposed. This incorrect response may reflect equating of risky behavior with actual knowledge of exposure.

A significant proportion of patients demonstrated a limited knowledge of HIV transmission. Factors associated with low HIV transmission knowledge were lower education, lower money spent on healthcare, higher clinic transportation costs, positive HIV status, and 
Citation: Hong SY, Thompson D, Wanke C, Omosa G, Jordan MR, et al. (2012) Knowledge of HIV Transmission and Associated Factors among HIVPositive and HIV-Negative Patients in Rural Kenya. J AIDS Clinic Res 3:170. doi:10.4172/2155-6113.1000170

Page 5 of 6

sex without a condom. Importantly, although those factors are mostly non-modifiable, these factors can be used to identify and target groups of patients at risk for low HIV transmission for education interventions.

Respondents whose education status was less than a Diploma were at risk for low knowledge scores, which corresponds with what was observed in the 2008-09 Kenya Demographics and Health Survey [12]. Similar associations between education and HIV knowledge have been described in other studies among general populations and in HIV patients $[18,20,21]$. This is an important finding since we found that a large proportion of our population were at this low education level.

Lowest quartile of money spent on healthcare was associated with low transmission knowledge. However, monthly income became insignificant after controlling for other factors. Therefore, we hypothesize that lower money spent on healthcare in this setting may be a marker for less access to healthcare instead of a marker for low income. To support this hypothesis, we found higher clinic transportation costs to be associated with low transmission knowledge. Therefore, access to care may be a risk factor for poor HIV transmission knowledge. Identifying these individuals will support targeted HIV education and prevention programs.

HIV positive participants had less knowledge of HIV transmission than those who were HIV negative and those who did not know their status. Therefore, we hypothesize that lower HIV transmission knowledge is a risk factor for infection with HIV. Interestingly, there was no difference in HIV transmission knowledge between those who knew they were HIV-negative and those who did not know their status, which may indicate that those who did not know their status were a lowrisk group. This pattern was mirrored when we evaluated transmission knowledge by site of enrolment i.e. those enrolled in general care had higher HIV transmission knowledge compared to those enrolled in VCT setting. It is possible that those enrolled in VCT may reflect a higher risk group that has lower knowledge about HIV transmission.

Participants who practiced sex without condoms had less knowledge of HIV transmission. These data may intuitively suggest that lower HIV transmission knowledge may lead to less condom use. However, it is difficult to interpret data about condom use without knowing whether or not the person not using a condom is in a stable monogamous relationship or has multiple sex partners. Nevertheless, it may be possible that after many years of HIV education in the communities, it is those who lag behind in HIV transmission knowledge that still practice unsafe sex.

This study is not without limitations. Since this was a cross-sectional study, causality between the factors analyzed cannot be inferred. Also, since the study population was a convenience sample from patients in a rural area in Kenya, these findings may not necessarily be generalizable to other resource-limited settings. However, results may be more relevant for HIV-positive and negative populations in Kenya, particularly in the rural areas.

While mean scores of HIV transmission is generally high, our findings speak in favor of targeting prevention and education initiatives in two distinct dimensions rather than accepting the generalized perception that Kenyans have a sufficiently high level of HIV transmission knowledge. First, is to target education programs at those individuals with lower education and lack of access to medical care. Secondly, education topics emphasized should match specific sub-topics to impart a more nuanced and accurate knowledge of HIV transmission and acquisition. Having correct information about one route of HIV infection does not preclude an individual from having misinformation about another route of HIV infection [13]. Therefore, these individuals having incomplete and therefore contradictory information may be the population still engaging in high-risk behaviors.

\section{Conclusions}

In conclusion, the results of this study conducted in rural Kenya demonstrate overall levels of HIV transmission knowledge in HIV-positive and HIV-negative participants comparable to those demonstrated in other resource-limited settings. However, these results also demonstrate some limitations in knowledge of HIV transmission in important topics and among a significant proportion of patients. A greater lack of knowledge was observed among especially vulnerable individuals affected by combinations of lower education and lack of access to care. This paper aims to alert public health providers that although overall levels of general HIV transmission knowledge may appear high, some vulnerable groups may be at an increased risk due to incomplete or contradictory HIV knowledge. ART programs in resource-limited settings should ensure adequate knowledge of HIV transmission in all areas and especially in their vulnerable populations to reduce the overall burden of HIV infection.

\section{Acknowledgments}

This research was supported by grants from the National Institute for Allergy and Infectious Disease: [NIH 1K23 Al097010-01A1 (SYH), NIH L30AI080268-02 (SYH), T32 Al007438-16 (SYH) and NIH K23 Al074423-05 (MRJ)]. Travel expenses for this study were supported in part by the Harold Williams Tufts Medical Student Research Fellowship (DT). Publication expenses for this manuscript were supported in part by a gift from the Christine E. Driscoll O'Neill and James M. Driscoll, Driscoll-O'Neill Charitable Foundation.

\section{References}

1. Smith Fawzi MC, Jagannathan F, Cabral J, Banares R, Salazar J, et al. (2006) Limitations in knowledge of HIV transmission among HIV-positive patients accessing case management services in a resource-poor setting. AIDS Care 18: $764-771$

2. Goel NK, Pathak R, Sharma MK, Gurpreet K, Kumar D (2008) A study of HIV/ AIDS: Knowledge and awareness among mothers of undergraduates of a medical college, Chandigarh(Ut). J Commun Dis 40: 215-217.

3. Ghosh S, Chhabra R, Springer C, Sharma SK (2008) A study of knowledge attitude, and sensitivity about HIVIAIDS among school teachers in northwestern Himalayas. Ethn Dis 18: S172-174.

4. Rahbar T, Garg S, Tripathi R, Gupta VK, Singh MM (2007) "Knowledge, attitude, behavior and practice (KABP) regarding HIVIAIDS among pregnant women attending PPTCT programme in New Delhi". J Commun Dis 39: 179-184.

5. Avants SK, Warburton LA, Hawkins KA, Margolin A (2000) Continuation of highrisk behavior by HIV-positive drug users. Treatment implications. J Subst Abuse Treat 19: 15-22.

6. O'Mahony P, Barry M (1992) HIV risk of transmission behaviour amongst HIVinfected prisoners and its correlates. Br J Addict 87: 1555-1560.

7. Wingood GM, DiClemente RJ, Mikhail I, Lang DL, McCree DH, et al. (2004) A randomized controlled trial to reduce HIV transmission risk behaviors and sexually transmitted diseases among women living with HIV: The WiLLOW Program. J Acquir Immune Defic Syndr 37: S58-67.

8. Crepaz N, Marks G (2002) Towards an understanding of sexual risk behavior in people living with HIV: A review of social, psychological, and medical findings. AIDS 16: 135-149.

9. Sowell RL, Seals BF, Cooper JA (1996) HIV transmission knowledge and risk behaviors of persons with HIV infection. AIDS Patient Care STDS 10: 111-115.

10. Joint United Nations Programme on HIVIAIDS [UNAIDS]. Global report UNAIDS report on the global AIDS epidemic.

11. http://data.worldbank.org/country/kenya

12. http://apps.who.int/medicinedocs/documents/s17116e/s17116e.pdf 
Citation: Hong SY, Thompson D, Wanke C, Omosa G, Jordan MR, et al. (2012) Knowledge of HIV Transmission and Associated Factors among HIVPositive and HIV-Negative Patients in Rural Kenya. J AIDS Clinic Res 3:170. doi:10.4172/2155-6113.1000170

13. London AS, Robles A (2000) The co-occurrence of correct and incorrect HIV transmission knowledge and perceived risk for HIV among women of childbearing age in El Salvador. Soc Sci Med 51: 1267-1278.

14. http://data.unaids.org/pub/Report/2010/kenya_2010_country_progress_ report_en.pdf

15. Kelly JA, St. Lawrence JS, Hood HV, Brasfield TL (1989) An objective test of AIDS risk behavior knowledge: Scale development, validation, and norms. J Behav Ther Exp Psychiatry 20: 227-234

16. Morton M, Nelson L, Walsh C, Zimmerman S, Coe RM (1996) Evaluation of a HIVIAIDS education program for adolescents. J Community Health 21: 23-35.
17. http://data.un.org/CountryProfile.aspx?crName=kenya\#Economic

18. Mahalakshmy T, Premarajan KC, Abdoul H (2011) Correlates of human immunodeficiency virus (HIV) related knowledge among HIV infected people. Indian J Dermatol Venereol Leprol 77: 37-41.

19. http://nascop.or.ke/library/PEP/infection_control_policy.pdf

20. Ambati BK, Ambati J, Rao AM (1997) Dynamics of knowledge and attitudes about AIDS among the educated in southern India. AIDS Care 9: 319-330.

21. Porter SB (1995) Public knowledge and attitudes about AIDS among adults in Calcutta, India. AIDS Care 5: 169-176. 